\title{
Ethical Considerations in Electronic Monitoring of the Cognitively Impaired
}

\author{
Y. Tony Yang, ScD, LLM, MPH, and Charles G. Kels, JD
}

Cognitive impairment afflicts an estimated 16 million people in the United States. Wandering is a concerning behavior associated with cognitive impairment, as it may threaten patient safety. The risks posed by wandering place severe burdens on both professional and informal caregivers, as well as law enforcement institutions throughout the United States. As such, location trackers that could reduce this burden have become increasingly prevalent. As with many assistive technologies, the substantial promise of location trackers is counterbalanced by potential pitfalls with respect to loss of privacy and autonomy. This article reviews the ethical issues raised by electronic monitoring of cognitively impaired persons, with the goal of transcending a narrow focus on decisional capacity in favor of a patient-centered framework that is applicable and adjustable at different stages of cognitive decline. Balancing the ethical principles of beneficence and respect in treating cognitively impaired persons goes beyond the necessary step of evaluating decision-making capacity to include partnering with families, caretakers, and cognitively impaired individuals who wander in a collaborative coalition of care. An approach emphasizing the individual needs of patients and caretakers is best suited to finding solutions that implement tracking technologies in ways that both protect and empower the cognitively impaired. ( $\mathrm{J}$ Am Board Fam Med 2017;30:258-263.)

Keywords: Caregivers, Cognitive Impairments, Dangerous Behavior, Ethics, Law Enforcement, Privacy, Risk

The number of people living with cognitive impairment is quickly increasing in the United States. The loss of cognitive function can be precipitated by various conditions, including Alzheimer disease, other forms of dementia, developmental disabilities, stroke, and traumatic brain injury. The associated impairment currently afflicts an estimated 16 million people in the United States. ${ }^{1}$ A prevalent behavioral characteristic is wandering, which describes "seemingly aimless or disoriented ambulation." "Roughly $60 \%$ of people suffering from Alz-

This article was externally peer reviewed.

Submitted 8 July 2016; revised 14 October 2016; accepted 1 November 2016.

From the Department of Health Administration and Policy, George Mason University, Fairfax, VA (YTY); the Division of Legislative Counsel, American Medical Association, Washington, DC (CGK); and the Judge Advocate General's Corps, US Air Force Reserve, Washington (CGK).

Funding: none.

Conflict of interest: none declared.

Corresponding author: Y. Tony Yang, ScD, LLM, MPH, Department of Health Administration and Policy, George Mason University, MS: 1J3, 4400 University Dr., Fairfax, VA 22030 (E-mail: ytyang@gmu.edu). heimer disease or another form of dementia wander. ${ }^{3}$ Although wandering is potentially beneficial to individuals with dementia as a source of exercise and access to the outdoors, it can also lead to falls, accidents, and even death from prolonged dehydration or environmental exposure. ${ }^{4}$ Over half of all wanderers missing for $>24$ hours die or are seriously injured, underscoring the repercussions of a delay in recovering lost individuals. ${ }^{3}$

The safety concerns associated with wandering are compounded by the tremendous burdens it places on loved ones, caregivers, and law enforcement agencies. On average, law enforcement agencies spend 9 hours locating a wandering patient with dementia, with a cost of $\$ 1500$ per hour of investigation. ${ }^{3}$ Technological innovations such as tracking devices offer the attractive potential to mitigate costs and improve safety. The market has responded to the dangers of wandering by introducing a variety of electronic surveillance products-using the Global Position System (GPS), radiofrequency location finders, alarms, mobile applications, and Bluetooth technology - to help lo- 
Table 1. Typology of Electronic Monitoring for Cognitively Impaired Individuals

\begin{tabular}{ll}
\hline Technology & \multicolumn{1}{c}{ Characteristics 7,8} \\
\hline GPS & Device receives satellite signals to calculate wearer's position, then relays it to the \\
appropriate party & - Highly accurate \\
- Covers large areas & - Requires clear path/unimpeded signals \\
- Enable virtual boundaries that trigger an alert when crossed \\
- Speed and accuracy can be augmented with Assisted GPS or Bluetooth \\
technology \\
- Examples: GPS Smart Shoe, Tracking System Direct wristwatch, Comfort Zone \\
mobile phone, Keruve wristwatch and receiver, Project Lifesaver Protect, and \\
Locate digital watch and receiver \\
- Device emits radio waves to a locating antenna \\
- Signal detectable on ground or by air \\
- Receiver must be tuned to the appropriate frequency \\
- Limited signal range \\
- Can be manually activated or used to create a virtual boundary \\
- Radiofrequency identification creates a "tag" to track individuals each time they \\
pass through an area \\
- Examples: Project Lifesaver locating device, LoJack Safety Net \\
- Device connects to the network and communicates with cellular towers \\
- Connects with the closest tower to conserve power \\
- Assisted GPS combines cellular and satellite positioning
\end{tabular}

GPS, global positioning system.

cate cognitively impaired individuals who elope from their caregivers ${ }^{5,6}$ (Table 1). It is estimated that between $3 \%$ and $5 \%$ of seniors in many technologically advanced countries are using mobile monitoring systems; the total number of individuals monitored by such telecare systems in North America and Europe is expected to jump from 450,000 in 2015 to nearly 3.4 million by 2021.9

For example, a patient with amnestic mild cognitive impairment who is still driving might benefit from wearing a location tracker. A location-based tagging system could be potentially life-saving for a patient with moderate Alzheimer disease who could wander outside alone and quickly become lost and exposed to various risks. These devices, which quickly locate the individual or notify a designated party when the individual has wandered, facilitate remote monitoring of the cognitively impaired, thereby providing peace of mind to many caregivers, protecting patients, and preserving public resources.

Given their role in alleviating anxiety over patient well-being, tracking devices have been widely embraced in both professional and informal care settings. ${ }^{10}$ Although a 2016 Canadian study found no data on the rate of adoption in dementia care, ${ }^{11}$ observational studies indicate the steady popularity of location trackers among caregivers. ${ }^{12}$ Decisions about whether and how to use the technology should remain a matter of ethical concern. This Ethics Feature reviews the sensitive issues raised by electronic monitoring of cognitively impaired people and then seeks to transcend a narrow focus on decisional capacity in favor of a patient-centered approach that embraces the cognitively impaired individual who wanders as a key collaborator in a coalition of care.

\section{For Whose Benefit?}

Assistive tracking technologies require striking a balance among competing values at the intersection of physical safety and personal liberty ${ }^{5,13,14}$ (Table 2). Used effectively, the additional safeguards provided by remote monitoring can allow individuals freedom to travel within a prescribed area, thereby mitigating the need to restrict movement via direct supervision or physical restraints. The inherent nature of remote surveillance threatens to offend dignity and erode privacy. The devices may be liable to overuse as a replacement for human contact.

The preferences of family caretakers are an important consideration, given the tremendous sacri- 
Table 2. Ethical Considerations and Recommendations in Electronic Tracking of Cognitively Impaired Individuals

\begin{tabular}{|c|c|c|}
\hline Ethical Principle & Concerns in Electronic Tracking & $\begin{array}{c}\text { Best Practices for Developing Care } \\
\text { Plans }\end{array}$ \\
\hline Liberty $^{15-18}$ & $\begin{array}{l}\text { - Virtual boundaries or alarms may function } \\
\text { as restrictions on movement } \\
\text { - Susceptibility of tracking technology to } \\
\text { overuse } \\
\text { - Appropriate balancing of technological } \\
\text { intervention against safety risk } \\
\text { - Constraining effect on choices and } \\
\text { activities } \\
\text { - Remote monitoring may prolong } \\
\text { independent living } \\
\text { - Enables less restrictive care settings } \\
\text { - Less intrusive than physical obstructions } \\
\text { - Reassuring safety net for individuals }\end{array}$ & $\begin{array}{l}\text { - Consider how electronic tracking may } \\
\text { obviate or postpone the necessity of } \\
\text { more restrictive care settings }{ }^{17} \\
\text { - Assess how remote monitoring may } \\
\text { replace physical barriers and enhance } \\
\text { freedom of movement }{ }^{18,19} \\
\text { - Incorporate tracking into care plans to } \\
\text { promote, rather than restrict, }_{\text {independence }}^{18}\end{array}$ \\
\hline Privacy $^{15,16,18,20}$ & $\begin{array}{l}\text { - Devices enable constant surveillance } \\
\text { - May conflict with individual's } \\
\text { past/present views on privacy } \\
\text { - Monitoring can facilitate care in more } \\
\text { private settings (eg, home vs nursing } \\
\text { home) } \\
\text { - Individual may value privacy differently } \\
\text { depending on the actor (eg, caregivers, } \\
\text { family, fellow patients) }\end{array}$ & $\begin{array}{l}\text { - Consider whether lower-technology } \\
\text { solutions that invade privacy less may } \\
\text { be sufficient (eg, registration systems, } \\
\text { personalized identification cards, } \\
\text { emergency response services that can } \\
\text { be activated by phone) } \\
\text { - Limit access to tracking data to only } \\
\text { those who need it and/or those whom } \\
\text { the individual wants to receive it }{ }^{15} \\
\text { - Ensure tracking system is secure }{ }^{17}\end{array}$ \\
\hline Dignity $^{15,16,18,20}$ & $\begin{array}{l}\text { - Tracking devices may have negative } \\
\text { connotations (eg, criminal justice, animals, } \\
\text { packages, "big brother") } \\
\text { - Perceptions of tracking devices may be } \\
\text { shaped by their association with wandering } \\
\text { or dementia } \\
\text { - Electronic monitoring may help prevent } \\
\text { stigmatizing episodes of wandering }{ }^{14}\end{array}$ & $\begin{array}{l}\text { - Differentiate "best interests" and "best } \\
\text { medical interests," especially where } \\
\text { the latter may impinge on the } \\
\text { former }{ }^{14} \\
\text { - Ensure devices are discrete }{ }^{18} \text { and part } \\
\text { of an overall plan that is } \\
\text { individualized and consistently } \\
\text { reassessed }\end{array}$ \\
\hline $\begin{array}{l}\text { Respect for persons, including } \\
\text { autonomy }{ }^{18,20-22}\end{array}$ & $\begin{array}{l}\text { - Individual's capacity to consent may be } \\
\text { compromised and fluctuating }{ }^{15} \\
\text { - How and when the cognitively impaired } \\
\text { individual is engaged in discussion can be } \\
\text { critical }^{20} \\
\text { - Efficacy of the device may rely on the } \\
\text { cognitively impaired person remembering } \\
\text { or choosing to affix it before walking }\end{array}$ & $\begin{array}{l}\text { - Avoid deception, in terms of both } \\
\text { hiding the device or concealing its } \\
\text { purpose from the cognitively impaired } \\
\text { individual }^{18} \\
\text { - Assess acceptable levels of risk to the } \\
\text { cognitively impaired individual, loved } \\
\text { ones, and caregivers } \\
\text { - Convene the cognitively impaired } \\
\text { person, loved ones, and caregivers as a } \\
\text { collaborative team when feasible and } \\
\text { as early in the stages of degenerative } \\
\text { impairment as possible } \\
\text { - Maximize the cognitively impaired } \\
\text { person's involvement and input, } \\
\text { irrespective of ability to consent }\end{array}$ \\
\hline Beneficence $^{21}$ & $\begin{array}{l}\text { - Wandering poses significant risks of } \\
\text { morbidity and mortality to cognitively } \\
\text { impaired persons but can also be beneficial } \\
\text { - Mitigating risks for cognitively impaired } \\
\text { persons may necessitate foregoing benefits } \\
\text { valued by the individual }{ }^{20,23} \\
\text { - Concerns about wandering may } \\
\text { compromise caregiver well-being }{ }^{15,18}\end{array}$ & $\begin{array}{l}\text { - Consider reasons for the cognitively } \\
\text { impaired person's wandering, } \\
\text { including whether it is a manifestation } \\
\text { of an unmet need (eg, exercise, } \\
\text { companionship) }{ }^{15} \\
\text { - Counsel that surveillance is not a } \\
\text { quick fix or substitute for personal } \\
\text { care, but part of a comprehensive care } \\
\text { plan }{ }^{15,17}\end{array}$ \\
\hline
\end{tabular}

fices and burdens in caring for cognitively impaired individuals. $^{15,25}$ While the vast majority of such caretakers operate according to the best interests of their loved ones, they tend to define those interests primarily in terms of physical protection. ${ }^{11,13}$
Some data contradict the notion that electronic care surveillance necessarily sacrifices liberty for safety. In 1 Swedish study, 16 of 17 seniors perceived such surveillance as positively affecting their ability to live independently, which in turn actually 
enhanced their sense of privacy. ${ }^{26}$ The seniors selected for that study, ranging from 68 to 96 years old, were living alone and capable of being interviewed, but they also were sufficiently vulnerable to health risks to have previously been provided with manually activated safety alarms. ${ }^{26}$ These findings provide a useful reminder that the intrusions of electronic tracking must be assessed in light of other, potentially more restrictive options for protecting the cognitively impaired. ${ }^{27}$ In "allowing the wanderer to wander," surveillance technologies may empower individuals with dementia by accommodating rather than restricting their behavior. ${ }^{19}$

\section{A Necessary Trade-off?}

The Universal Declaration of Human Rights enshrines both privacy and freedom of movement as fundamental rights. ${ }^{16}$ Cognitively impaired individuals represent a vulnerable population whose rights must be protected along with their safety, especially in the context of determining how to use progressive technologies. Electronic surveillance issues in the United States have largely been adjudicated in the criminal context, focusing on the constitutional right to be free from arbitrary government intrusions, not from private encroachments. ${ }^{28}$ Technology has compelled the evolution of constitutional doctrine by facilitating the pervasiveness of government surveillance. Reasonable expectations of privacy ${ }^{29}$ may diminish as the public accepts trade-offs for convenience; alternatively, new technological encroachments may necessitate expanding traditional safeguards. ${ }^{30}$

In the context of care for the cognitively impaired, private litigation over location monitoring remains unlikely because of the high level of support among afflicted individuals' family members. ${ }^{11}$ Familial caretakers are often more enthusiastic about the technology than health care professionals. ${ }^{15}$ Families tend to support the use of electronic tracking most strongly when they are directly responsible for their loved ones' care. ${ }^{13}$ The management of wandering requires an appraisal of risk tolerance among stakeholders, including patients, families, and the caregiving team. ${ }^{23}$

It is not always clear-cut whether the safety benefits of surveillance outweigh the risks to personal liberty. ${ }^{17}$ Additional research could shed light on the experiences of both caregivers and cognitively impaired individuals with electronic tracking. ${ }^{15}$
Determining the extent to which patients' and caregivers' preferences align can inform the debate over whether location monitoring requires a tradeoff of privacy for security, or whether it can be squared with the liberty interests of cognitively impaired individuals on a stand-alone basis. To date, the dominance of the discussion by professional commentators risks overlooking the "actual experience of usage" by both patients and carers, thereby skewing the analysis toward presumed tension even where the effects of electronic tracking may be perceived as mutually beneficial by all parties. ${ }^{15}$ The "experience-distorting technical language" often used to describe family caregiving should not obscure the "close experiential language of actually doing it." 31

\section{Beyond Decisional Capacity}

Providing medical informed consent requires capacity, or the ability to comprehend information and communicate clear preferences about proposed courses of action. ${ }^{32}$ A central challenge of caring for cognitively impaired individuals is that the legal framework defines capacity at any point in time as either "present" or "absent." Compromised and fluctuating capacity does not fit neatly into this dichotomous construct, with patient choice at 1 end and proxy decision making on the other. ${ }^{15}$ Individuals whose wandering behavior necessitates electronic monitoring are likely to be experiencing moderate to severe cognitive impairment that situates them squarely in this nebulous zone. Borderline and variable capacity in neurodegenerative dementias underscores the importance of approaching the affected individual at the right time and in the right way in order to maximize the potential for meaningful engagement. ${ }^{20}$

In the absence of advance planning documents wherein the individual made choices before their capacity deteriorated, surrogate decision-makers are often left to navigate the terrain of deciphering what the individual would have wanted (substituted judgment) or deciding what is in the individual's best interests. ${ }^{33} \mathrm{~A}$ joint decision-making model that seeks and accords weight to the input of individuals with cognitive impairment can help bridge the gap between situations where capacity is variable and diminished, and the onset of consistent need for proxy decision making. ${ }^{15,20}$ 
Cases where the patient readily can and does provide informed consent to electronic surveillance are straightforward but may be atypical. ${ }^{15}$ Irrespective of whether the cognitively impaired individual has been legally declared incompetent or clinically deemed incapacitated, their input into health care decisions should be maximized through active physician-patient collaboration. People with compromised decisional capacity can retain the capacity to express values, preferences, and goals. ${ }^{24}$ In fostering this dialog, physicians balance the ethical principles of beneficence and respect for persons, which incorporates autonomy. ${ }^{21}$ An incompetent or incapacitated patient's rejection of electronic tracking may justifiably yield to competing priorities, including safety, appropriate care, and the feasible burden on caregivers. ${ }^{34}$ Deception is usually inappropriate. ${ }^{18}$

A key principle animating decisions about the use of electronic tracking tools for cognitively impaired persons is to recognize that autonomy encompasses more than decisional capacity, and does not cease to matter as capacity wanes. When physicians speak of patient autonomy, they tend to mean both the capacity to make independent choices and the values and beliefs that make individuals who they are. ${ }^{35}$ As the former deteriorates, protective interventions (such as assistive technologies) may prove necessary to keep individuals safe. The latter retains its ethical force across the capacity continuum.

Translated into clinical guidance, the persistence of patient autonomy means that the tenets of patient-centered care remain relevant even when the lucidity of the individual is compromised. Properly balancing safety and autonomy includes soliciting the engagement of the cognitively impaired individual in discussions around electronic tracking, even when obtaining informed consent is not possible. When patients and families are considering the use of surveillance tools, certain key principles can help physicians act as educators and advocates for cognitively impaired individuals (Table 2).

\section{Conclusions}

The problem of wandering is real, with negative repercussions at the individual, caregiver, and societal levels. In view of the large and growing population of cognitively impaired individuals, electronic tracking devices may become integral to the prevention and mitigation of this phenomenon. As researchers evaluate the impact, utility, and costeffectiveness of using these progressive technologies, it is imperative to engage simultaneously the profound ethical issues at play and to inquire how electronic surveillance can either erode or augment the liberty and privacy of tracked individuals. ${ }^{14}$

Although no technology can ever replace the centrality of human care, electronic monitoring devices represent an additional tool to assist families, facilities, and public safety agencies in countering the threat posed by wandering. Various organizations have promulgated helpful guidance that can serve as a starting point for making decisions about the use of surveillance tools. ${ }^{17,18}$ These statements do not provide prescriptive rules, but rather give overviews of the practical and ethical considerations in deciding when and how to implement electronic monitoring.

Balancing the safety and autonomy of cognitively impaired people entails more than just evaluating their decision-making capacity; it also requires implementing tracking technologies in ways that accord with their dignity as individuals. An approach emphasizing the individual needs of patients and caretakers is best suited to finding solutions that both protect and empower the cognitively impaired. Physicians, as counselors to patients and their loved ones, are uniquely suited to ensure that cognitively impaired individuals' voices are not lost, even when their capacity to consent is reduced.

To see this article online, please go to: http://jabfm.org/content/ 30/2/258.full.

\section{References}

1. Centers for Disease Control and Prevention. Cognitive impairment: a call for action, now! February 2011. Available from: http://www.cdc.gov/aging/ pdf/cognitive_impairment/cogimp_poilicy_final.pdf. Accessed May 12, 2016.

2. Cipriani G, Lucetti C, Nuti A, Danti S. Wandering and dementia. Psychogeriatrics 2014;14:135-42.

3. Alzheimer's Foundation of America. Lost and . . . found. A review of available methods and technologies to aid law enforcement in locating missing adults with dementia. A report by the Alzheimer's Foundation of America, June 2012. Available from: https:// www.alzfdn.org/documents/Lost\&Found_forweb. pdf. Accessed May 12, 2016.

4. Beattie ER, Song J, LaGore S. A comparison of wandering behavior in nursing homes and assisted living facilities. Res Theory Nurs Pract 2005;19: 181-96.

5. Niemeijer AR, Frederiks BJ, Riphagen II, Legemaate J, Eefsting JA, Hertogh CM. Ethical and practical 
concerns of surveillance technologies in residential care for people with dementia or intellectual disabilities: an overview of the literature. Int Psychogeriatr 2010;22:1129-42.

6. Bishop K. Growth business: GPS tracking . . . the elderly. March 12, 2014. Available from: http:// www.cnbc.com/2014/03/11/growth-business-gpstracking-the-elderly.html. Accessed May 12, 2016.

7. US Department of Justice, Bureau of Justice Assistance. Lost and found: understanding technologies used to locate missing persons with Alzheimer's or dementia. March 2014. Available from: https://www. bja.gov/Publications/PLI-Lost_and_Found.pdf. Accessed September 27, 2016.

8. Rasquin SMC, Willems C, de Vlieger S, Geers RPJ, Soede M. The use of technical devices to support outdoor mobility of dementia patients. Technol Disabil 2007;19:113-20.

9. Berg Insight. People monitoring and safety solutions. 4th ed. April 2016. Available from: http:// www.researchandmarkets.com/research/hkmg8f/ people_monitoring. Accessed September 25, 2016.

10. Eltis K. Predicating dignity on autonomy? The need for further inquiry into the ethics of tagging and tracking dementia patients with GPS technology. Elder Law J 2005;13:387-415.

11. Topfer L; Canadian Agency for Drugs and Technologies in Health. GPS locator devices for people with dementia. September 2016. Available from: https:// www.cadth.ca/dv/gps-locator-devices-people-dementia. Accessed September 25, 2016.

12. Milne H, van der Pol M, McCloughan L, et al. The use of global positional satellite location in dementia: a feasibility study for a randomized controlled trial. BMC Psychiatry 2014;14:160.

13. Landau R, Werner S. Ethical aspects of using GPS for tracking people with dementia: recommendations for practice. Int Psychogeriatr 2012;24: $358-66$.

14. Hughes JC, Louw SJ. Electronic tagging of people with dementia who wander. BMJ 2002;325:847-8.

15. White EB, Montgomery P. Electronic tracking for people with dementia: an exploratory study of the ethical issues experienced by carers in making decisions about usage. Dementia (London) 2014;13: 216-32.

16. United Nations. The universal declaration of human rights. December 10, 1948. Available from: http:// www.un.org/en/documents/udhr/. Accessed May 12, 2016.

17. Alzheimer's Association. Electronic tracking. Available from: http://www.alz.org/documents_custom/ statements/electronic_tracking.pdf. Accessed May 12, 2016.

18. Alzheimer's Society. Safer walking technology. Available from: http://www.alzheimers.org.uk/site/ scripts/documents_info.php?documentID =579. Accessed May 12, 2016.
19. Wigg JM. Liberating the wanderers: using technology to unlock doors for those living with dementia. Sociol Health Illn 2010;32:288-303.

20. Nuffield Council on Bioethics. Dementia: ethical issues. October 2009. Available from: http://nuffieldbioethics.org/project/dementia/. Accessed September 27, 2016.

21. US Department of Health, Education, and Welfare. The Belmont report: ethical principles and guidelines for the protection of human subjects of research. April 18, 1979. Available from: http://www. hhs.gov/ohrp/regulations-and-policy/belmontreport/index.html. Accessed October 13, 2016.

22. ABIM Foundation, American Board of Family Medicine; ACP-ASIM Foundation, American College of Physicians-American Society of Internal Medicine; European Federation of Internal Medicine. Medical professionalism in the new millennium: a physician charter. Ann Intern Med 2002;136:243-6.

23. Robinson L, Hutchings D, Corner L, et al. Balancing rights and risks: conflicting perspectives in the management of wandering in dementia. Health Risk Soc 2007;9:389-406.

24. Molinari V, McCullough LB, Coverdale JH, Workman R. Principles and practice of geriatric assent. Aging Ment Health 2006;10:48-54.

25. Livingston G, Leavey G, Manela M, et al. Making decisions for people with dementia who lack capacity: qualitative study of family carers in UK. BMJ 2010;341:c4184.

26. Essen A. The two facets of electronic care surveillance: an exploration of the views of older people who live with monitoring devices. Soc Sci Med 2008; 67:128-36.

27. Rowe MA, Feinglass NG, Wiss ME. Persons with dementia who become lost in the community: a case study, current research, and recommendations. Mayo Clin Proc 2004;79:1417-22.

28. United States v. Fones, 132 S. Ct. 945 (2012).

29. Katz v. United States, 389 U.S. 347 (1967).

30. Friedman B. Privacy, technology and law. New York Times, January 29, 2012, SR5.

31. Kleinman A. Caregiving: the odyssey of becoming more human. Lancet 2009;373:292-3.

32. Paterick TJ, Carson GV, Allen MC, Paterick TE. Medical informed consent: general considerations for physicians. Mayo Clin Proc 2008;83:313-9.

33. Torke AM, Alexander GC, Lantos J. Substituted judgment: the limitations of autonomy in surrogate decision making. J Gen Intern Med 2008;23:1514-7.

34. Coverdale J, McCullough LB, Molinari V, Workman R. Ethically justified clinical strategies for promoting geriatric assent. Int $\mathrm{J}$ Geriatr Psychiatry 2006;21:151-7.

35. Brudney A. Choosing for another: beyond autonomy and best interests. Hastings Cent Rep 2009; 39:31-7. 